\title{
Serum Immunoglobulin G, IgM And IgG: IgM Ratio as Predictors for Outcome of Childhood Nephrotic Syndrome
}

\author{
Shereen Ekram Mohammed, Ramadan Abo El Hassan Ahmed, \\ Abdelrahim Abdrabou Sadek.
}

Department of Pediatrics, Faculty of Medicine, Sohag University, Egypt

\begin{abstract}
Background: Nephrotic syndrome (NS) comes at the top of most prevalent kidney morbidities in Africa constituting 40\% of renal disorders in Egypt. Minimal changes NS (MCNS) representing $88 \%$ of patients with NS. Glomerular risk factors of NS can be classified into either primary or secondary. Aim of the Work: to estimate serum levels of IgG, IgM, in NS cases comparing them with those of healthy children in addition to detect the relationship between $\operatorname{IgG} / \operatorname{IgM}$ ratio and response to treatment with steroids. Patients and Methods: This was an observational cohort prospective study was conducted on 60 subjects recruited from Pediatric Department, Sohag University Hospital during a period of one year from 2015 to 2016. All included patients underwent detailed history taking, medical examination, laboratory investigations, serum albumin, complete blood count with differential white blood cell count, serum immunoglobulin $\mathrm{G}$, immunoglobulin $\mathrm{M}$, were measured in patient groups; group A included 15 patients. They had NS, received steroids for 8 weeks and not respond. They were steroid-resistant Ns (SRNS). group B included 15 patients with SSNS with infrequent relapse, group C included 15 patients with SSNS with frequent relapse, group D included 15 healthy children as a control group. Results: a statistically significant difference was found between groups as regards $\operatorname{IgG} / \mathrm{IgM}$ ratio. Conclusion: Serum IgM and IgG levels have prognostic value in patients with nephrotic syndrome and can predict the outcome and the frequency of recurrence of the disease. There is a close relationship between the degree of albuminuria and the levels of serum IgG and $\mathrm{M}$.
\end{abstract}

Keywords: Serum Immunoglobulin G, IgM, IgG: IgM, Childhood Nephrotic Syndrome

\section{Introduction}

Nephrotic syndrome (NS)is caused by the increasing loss of albumin, proteins and other plasma components having similar mass in patients complaining from syndrome complex of decreased levels of serum albumin, increased levels of blood lipid, lipids in the urine and edema (Macé and Chugh, 2014).

It is considered the most prevalent kidney disease in Africa with a percentage of $40 \%$ of renal morbidities inside Egypt. Minimal change NS (MCNS) is $88 \%$ of patients with NS (Tapia and Bashir, 2018).

Glomerular risk factors of NS can be classified generally to primary or secondary causes. Primary nephrotic syndrome (PNS) or idiopathic nephrotic syndrome (INS), is usually associated with glomerular comorbidities in kidney away from systemic etiologies. A wide variety of glomerular lesions can be seen in INS (Cil and Perwad, 2018).

INS is divided into steroid-sensitive (SSNS) (Pokrajac et al., 2018) and steroid-resistant nephrotic syndrome (SRNS) (Nourbakhsh and mak, 2017) taking into account that response to steroid therapies is highly correlated with tissue subtype and disease progression 
prognosis. The prominent work in this regard is the study of pediatric nephrotic syndrome, the International Study of Kidney Disease in Children (ISKDC), revealed that the great portion of children preadolescence with INS had MCNS on their renal biopsies.

Recently, various studies have been conducted on NS and immunity. They can be classified into two main divisions, i.e., cellular immunity and humoral immunity. It was first postulated that MCNS could be caused by a systemic dysfunction of T-cells(de Fátima Pereira et al., 2014).

Serum IgG and IgA levels in cases with MCNS decrease while serum IgM level increases. It was stated that the principal defect in idiopathic NS is the shortage of the T-cell role and function linking between the stage of $\operatorname{IgM}$ synthesis and IgG synthesis found abnormal levels of immune globulins both inactive and in remission stages; however, increased levels of circulating immune complexes have been observed only relapse periods(El Mashad et al., 2017).

As it is the case with albumin, $\operatorname{IgG}$ is usually lost in the urine, with low serum concentration and increased fractional rates of its catabolism, denoting the role of the kidney in contribution to IgGconsumption in cases suffering from proteinuria (Mravljak et al., 2013). Multiple fashions are usually detected in IgG synthesis responses in patients with NS and may be declined, leading to low serum concentrations. On the other hand, serum concentrations of the highmolecular weight immunoglobulin IgM increase, like the serum concentration of many other high-molecular weight liver-derived proteins (Kaysen and Al Bender, 1990).

Studies have been suggested that hypogammaglobulinemia of steroidsensitive NS (SSNS) is identified by different components of IgG subclasses. In remissions, serum levels of $\mathrm{IgG}-1$, IgG-3 are decreased, whereas low concentrations of IgG-2 might be key feature of hypogammaglobulinemia in SSNSremissions(Youssef et al.,2011).

\section{Aim of the Work}

The aim of this study was to estimate serum levels of $\operatorname{IgG}$, IgM, in NS cases comparing them with those of healthy children in addition to detect the relationship between $\operatorname{IgG/IgM~ratio~and~}$ response to treatment with steroids.

\section{Patients and Methods}

This observational cohort prospective study was conducted on 60 subjects recruited from Pediatric Department, Sohag University Hospital during a period of one year from 2015 to 2016.

Neonates under the age of 1 year of age children above fifteen years, and those having systemic diseases, hepatitis B or C viruses were excluded from the current study.

\section{Methods:}

All included patients were subjected to full history taking, clinical examination, laboratory studies, serum albumin, complete blood count with differential white blood cell count, serum immunoglobulin $\mathrm{G}$, immunoglobulin $\mathrm{M}$, were measured in patient groups; group A included 15 patients. They had NS, received steroids for 8 weeks and not respond, They were steroid-resistant Ns (SRNS). Group B included 15 patients with SSNS with infrequent relapse, group C included 15 patients with SSNS with frequent relapse, group D included 15 healthy children, control groups.

The patients received their treatment in our department according to their presentation and were followed up.

\section{Statistical Analysis:}

Statistical package for social science (SPSS) was applied for data analysis. The data was presented in mean and standard deviation in the case of normally distributed data. The data were presented as median and inter-quartile range in case 
SOHAG MEDICAL JOURNALSerum Immunoglobulin G, IgM And IgG:IgM Ratio as Predictors Vol. 23 No. 3July 2019ShereenEkram Mohammed

of not- normally distributed data.Student$\mathrm{t}$-test was used to determine the difference between groups in case of normally distributed data whereas Man-Whitney test (U test) was used in case of not normally distributed data.

\section{Results}

\begin{tabular}{|c|c|c|c|c|c|c|}
\hline \multirow[b]{2}{*}{ Demographic data } & \multicolumn{4}{|c|}{ Groups } & \multirow[b]{2}{*}{ F/x2\# } & \multirow[b]{2}{*}{ p-value } \\
\hline & $\begin{array}{c}\text { Group (A) } \\
(\text { no=15) }\end{array}$ & $\begin{array}{c}\text { Group (B) } \\
(\text { no=15) }\end{array}$ & $\begin{array}{c}\text { Group }(C) \\
(n o=15)\end{array}$ & $\begin{array}{l}\text { Control } \\
(\text { no=15) }\end{array}$ & & \\
\hline \multicolumn{7}{|l|}{\begin{tabular}{|l} 
Age (years) \\
\end{tabular}} \\
\hline Rage & $1-15$ & $1-15$ & $1-15$ & $1-15$ & \multirow{2}{*}{0.767} & \multirow{2}{*}{0.449} \\
\hline Mean \pm SD & $8.80 \pm 2.73$ & $8.40 \pm 2.60$ & $7.60 \pm 2.36$ & $9.60 \pm 2.98$ & & \\
\hline \multicolumn{7}{|l|}{ Sex } \\
\hline Male & $5(33.3 \%)$ & $6(40.0 \%)$ & $5(33.3 \%)$ & $6(40.0 \%)$ & \multirow{2}{*}{$0.287 \#$} & \multirow{2}{*}{0.962} \\
\hline Female & $10(66.7 \%)$ & $9(60.0 \%)$ & $10(66.7 \%)$ & $9(60.0 \%)$ & & \\
\hline
\end{tabular}

Table (1): Comparison between groups as regard demographic data.

This table shows no statistically significant difference between groups as regards demographic data.

\begin{tabular}{|c|c|c|c|c|}
\hline \multirow{2}{*}{ Parameters } & \multicolumn{2}{|c|}{ IgG (g/L) } & \multicolumn{2}{|c|}{ ANOVA test } \\
\hline & Mean & \pm SD & $\mathbf{F}$ & p-value \\
\hline Group (A) & 2.31 & 1.58 & \multirow{4}{*}{12.441} & \multirow{4}{*}{$<0.001$} \\
\hline Group (B) & 5.90 & 1.18 & & \\
\hline Group (C) & 4.11 & 1.38 & & \\
\hline Control & 11.80 & 2.50 & & \\
\hline
\end{tabular}

Table (2): Comparison between groups as regard $\operatorname{IgG}(\mathrm{g} / \mathrm{L})$.

This table showed a highly statistically significant difference between groups as regard $\operatorname{IgG}(\mathrm{g} / \mathrm{L})$.

\begin{tabular}{|c|c|c|c|c|}
\hline \multirow{2}{*}{ Parameters } & \multicolumn{2}{|c|}{$\operatorname{IgM}(\mathrm{g} / \mathrm{L})$} & \multicolumn{2}{|c|}{ ANOVA test } \\
\hline & Mean & \pm SD & $\mathbf{F}$ & p-value \\
\hline Group (A) & 1.70 & 1.10 & \multirow{4}{*}{0.498} & \multirow{4}{*}{0.622} \\
\hline Group (B) & 1.50 & 0.70 & & \\
\hline Group (C) & 1.60 & 0.90 & & \\
\hline Control & 1.50 & 0.60 & & \\
\hline
\end{tabular}

Table (3): Comparison between groups as regard IgM (g/L).

This table showed no statistically significant difference between groups as regard $\operatorname{IgM}$ $(\mathrm{g} / \mathrm{L})$.

\begin{tabular}{|l|c|c|c|c|}
\hline \multirow{2}{*}{ Parameters } & \multicolumn{2}{|c|}{ IgG/IgM ratio } & \multicolumn{2}{c|}{ ANOVA test } \\
\cline { 2 - 3 } & Mean & $\mathbf{\pm S D}$ & \multirow{2}{*}{ F } & p-value \\
\hline Group (A) & 1.80 & 1.75 & & \\
\hline Group (B) & 4.82 & 2.36 & \multirow{2}{*}{3.980} & \multirow{2}{*}{$\mathbf{0 . 0 0 4}$} \\
\hline Group (C) & 3.31 & 2.05 & & \\
\hline Control & 9.30 & 4.70 & & \\
\hline
\end{tabular}

Table (4): Comparison between groups as regards IgG/IgM ratio.

This table showed a statistically significant difference between groups as regard the IgG/IgM ratio.

This table showed a highly statistically significant difference between groups as regards $\mathrm{IgG} / \mathrm{IgM}$ ratio. 


\section{Discussion}

Nephrotic syndrome is generally associated with massive proteinuria, hypoalbuminemia, and edema; an additional feature such as hyperlipidemia is also usually present (GbadegesinandSmoyer, 2008).

Infection is the major complication of nephrotic syndrome. Children in relapse are an increased risk of developing bacterial infections because of urinary losses of $\mathrm{Ig}$ and properdin factor $\mathrm{B}$, defective cell-mediated immunity, immunosuppressive therapy, malnutrition, and edema acting as a potential culture medium for organisms(Han et al., 2010).

Nephrotic syndrome is an immunemediated kidney disease associated with T-cell dysfunction and secondary disturbance of B-cell that leads to changes in the levels of $\operatorname{IgG}$ and $\mathrm{M}$ (Srivastava, et al., 2005).

Accordingly, assessment of $\mathrm{IgG}$ and IgM levels and their ratio as well as the correlation of these values with clinical response to steroid treatment, remission, and adherence is a vital and essential step in follow up and management procedures and to reach the desired results(Srivastava, et al., 2005).

The aim of this study was to estimate serum $\operatorname{IgG}$ and $\operatorname{IgM}$ levels in children with nephrotic syndrome on the presentation of the patient to evaluate response to therapy and the rate of relapse.

The results of this study showed that there were no statistically significant differences between the groups studied in demographic data and anthropometric measurements, and this result was in agreement with that reported by $\boldsymbol{E l}$ Shafie et al. (2007). Thus, the effect of age and sex can be excluded as a factor explaining the difference in their medical and biochemical characteristics.

Patients with the nephrotic syndrome had unusual susceptibility to encapsulated bacterial infection. Studies showed that there are changes in the serum IgG, IgM levels associated with proteinuria in nephrotic patients. According to studies, changes in the serum Ig levels can be attributed to either T-cell dysfunction and/or increased urinary excretion of albumin(Nariman and Azat., 2012).

Chen et al.,(1987) and Sahali (2002) reported changes in serum IgG and IgM in children with nephrotic syndrome; this is in agreement with our study. These results were not in agreement with those reported by Beale et al (1983)who reported that in-vivo production of Ig, especially $\mathrm{IgG}$, was either normal or increased. The difference in these results may be because of differences in age, number, and pathological types of nephrotic syndrome of the patients studied.

Chen et al. (1987) reported that boosted activity of suppressor T-cell leads to an elevation in serum $\operatorname{IgM}$ and against a decrease in serum IgG production in NS children.

However, Kaysen and Al-Bander (1990)reported that in nephrotic syndrome, there is increased urinary excretion of albumin and $\mathrm{IgG}$ accompanied by a decrease in their serum concentration. Our study showed that an increase in albuminuria is accompanied by a reduction in serum IgG levels. These results were in agreement with those reported by Siberil et al (2007).

High-molecular-weight IgM increases to defend serum protein concentration and oncotic pressure. Hypoalbuminemia associated with nephrotic syndrome is thus likely to affect the serum IgM level. This explains the negative correlation between serum albumin levels and serum IgM levels.

Overproduction of high-molecularweight proteins is observed in NS; for example lipoproteins cause hyperlipidemia and are not to be lost in 
urinary to maintain the colloid osmotic pressure. Our study illustrated a significant relation between serum cholesterol levels and serum IgG of the nephrotic group. These results were in agreement with those reported by Kemper et al (2002)and Siberia et a (2007).

After 1 year of follow-up, we found a significant correlation between IgG and IgM serum levels at the initial presentation with response to therapy and rate of relapse. The higher the serum IgM and the lower the serum IgG levels at presentation, the higher the rate of relapse as reported by Roy et al (2009).

Ahmed et al (2011) found that a low serum IgG level at the onset showed no significant relation with the rate of relapse.

In conclusion, IgG serum level is decreased and IgM serum level is increased in all patients with nephrotic syndrome compared with healthy children. Ig levels can be used as an important serological marker to predict responsiveness to treatment in different types of nephrotic syndrome. Serological markers for rapid diagnosis are very important in the management of the disease.

The low level of IgG in nephrotic syndrome as reported in our study could be attributed to many factors such as their low molecular weight causing their excess loss in urine and isotype switching defect from IgM-secreting cells to IgG-secreting cells.

Down-regulation of the interleukin (IL12) receptor $P 2$ subunit during relapse attenuates $\mathrm{Th}$. Increased production of IL-13 induces Th2 cytokine during relapse.

The decrease in Th1 induces:

The decrease in Th induces:

A decrease in IL-2, INF- $\gamma$ Decrease in IgG The decrease in IL-5 Decrease in $\operatorname{IgA}$

Increase in Th induces:
Increase in IL-4, IL-5 B-cell proliferation

Increase in IL-4, IL-5 Increase in IgM

Increase in IL-4 Increase in IgE

Increase in IL-13 Proteinuria

\section{Conclusion}

Nephrotic syndrome is an immunity kidney disorder characterized by T-cell dysfunction and secondary disturbance of B-cell leading to major changes in IgG and $M$ levels.

Therefore, the assessment of $\mathrm{IgG}$ and IgM levels and their ratio in addition to the relation of these values with clinical response to steroid therapy, remission, and dependency is considered significant to observe management methods and to obtain the target outcome.

Infection is one of the main complications of nephrotic syndrome. During a relapse, children are at increased risk of having infections caused by bacteria because of urinary losses of $\mathrm{Ig}$ and properdin factor B, defective cell-mediated immunity, immunosuppressive therapy, malnutrition, and edema providing a potential culture medium for organism production.

A prognostic value can be presumed by serum $\operatorname{IgM}$ and $\operatorname{IgG}$ levels in cases with NS and can predict the outcome and the frequency of recurrence of the disease. There is an affirmed relation between the degree of albuminuria and the levels of serum IgG and M.

\section{References}

1. Cil O, Perwad F. Monogenic causes of proteinuria in children. Frontiers in medicine. 2018;5:55.

2. de Fátima Pereira W, Brito-Melo GE, Guimarães FT, Carvalho TG, Mateo EC, e Silva AC. The role of the immune system in idiopathic nephrotic syndrome: a review of clinical and experimental 
studies. Inflammation Research. 2014;63

(1):1-2.

3. El Mashad GM, Ibrahim SA, Abdelnaby SA. Immunoglobulin G and $\mathbf{M}$. levels in childhood nephrotic syndrome: two centers Egyptian study. Electronic physician. 2017;9(2):3728.

4. Macé C, Chugh SS.Nephrotic syndrome: components, connections, and angiopoietin-like 4-related therapeutics. Journal of the American Society of Nephrology. 2014;25(11):2393-8.

5. Mravljak M, Vizjak A, Ferluga D, Pajek J, Kovac D, Skoberne A, Rigler AA, Kveder R, Kosir A, Lindic J. Urinary Immunoglobulin $\mathrm{G}$ to Albumin Ratio and N-Acetyl-Beta-DGlucosaminidase as Early Predictors of Therapeutic Response in ANCAAssociated Glomerulonephritis. PloS one. 2013; 8(12):e81703.
6. Nourbakhsh N, Mak RH. Steroidresistant nephrotic syndrome: past and current perspectives. Pediatric health, medicine, and therapeutics. 2017;8:29.

7. Pokrajac D, Kamber AH, Karasalihovic Z. Children with SteroidResistant Nephrotic Syndrome: A SingleCenter Experience. Material socio-media. 2018;30(2):84.

8. Tapia C, Bashir K.Nephrotic Syndrome. InStatPearls [Internet] 2018 Nov 10. StatPearls Publishing.

9. Youssef DM, Salam SA, Karam RA. Prediction of steroid response in nephrotic syndrome by humoral immunity assessment. Indian journal of nephrology. 2011;21(3):186. 